\title{
Comparison of Therapeutic Effectiveness Between Shoulder Distention Arthrography With Translation Mobilization and Distention Arthrography Alone in Patients With Frozen Shoulder
}

\author{
Gi Young Park, MD, PhD, Dong Rak Kwon, MD, PhD, Dae Gill Kwon, MD, Jae Hwal Rim, MD \\ Department of Rehabilitation Medicine, Catholic University of Daegu School of Medicine, Daegu, Korea
}

Objective To evaluate the efficacy of distention arthrography (DA) alone and in combination with translational mobilization (TM) for treatment of patients with frozen shoulder (FS).

Methods Eighty-five patients diagnosed with unilateral FS (freezing or frozen stage) were included. Forty-one patients were treated with DA and TM (group 1) and 44 patients with DA alone (group 2). Clinical assessments including visual analogue scale (VAS), Cyriax stage, and shoulder passive range of motion (PROM) including forward flexion, abduction, external rotation, and internal rotation were measured at baseline, 1 month, and 3 months following treatment.

Results There were no significant differences in gender, side affected, symptom duration, presence of diabetes mellitus, VAS score, Cyriax stage, or shoulder PROM between the two patient groups at baseline. Compared with baseline metrics, patients in both groups demonstrated significantly improved outcome parameters at two posttreatment time points. However, mean all shoulder PROMs were significantly greater, and mean VAS score and Cyriax stage were lower in patients treated with DA and TM than in those treated with DA alone group at two posttreatment time points. At these times, mean interval change of all outcome parameters was significantly greater with DA and TM than DA alone. No serious complications were observed following treatment in either patient group.

Conclusion Compared with DA alone, DA combined with TM more effectively alleviates shoulder pain and increases PROM in patients with freezing or frozen stage FS.

Keywords Frozen shoulder, Distention arthrography, Translational mobilization

Department of Rehabilitation Medicine, Catholic University of Daegu School of Medicine, 33 Duryugongwon-ro 17-gil, Nam-gu, Daegu 42472, Korea. Tel: +82-53-650-4894, Fax: +82-53-622-4687, E-mail: 4everljh@hanmail.net

ORCID: Gi Young Park (http://orcid.org/0000-0003-0056-1556); Dong Rak Kwon (http://orcid.org/0000-0003-4728-930X); Dae Gil Kwon (http://orcid. org/0000-0002-8423-8045); Jae Hwal Rim (http://orcid.org/0000-0002-4176-3253).

() This is an open-access article distributed under the terms of the Creative Commons Attribution Non-Commercial License (http://creativecommons.org/ licenses/by-nc/4.0) which permits unrestricted noncommercial use, distribution, and reproduction in any medium, provided the original work is properly cited. Copyright $\odot 2018$ by Korean Academy of Rehabilitation Medicine 


\section{INTRODUCTION}

Frozen shoulder (FS) is characterized by the gradual onset and painful limitation of shoulder. First described by Duplay in 1872 as a condition that restricted abduction and external rotation, Codman subsequently expanded the definition of FS to include a gradual onset of shoulder pain, inability to sleep on the affected side, and limitation in both active and passive elevation and external rotation with a normal radiological finding [1].

The pathophysiology of FS includes chronic synovial inflammation followed by synovial tissue proliferation, thickening, and contraction [2]. Neviaser [2] reported that the most important pathology of the FS was a thickening and contraction of the joint capsule, which becomes adherent to the humeral head, thus causing limited joint mobility. However, some arthroscopic studies reported that no distinct intra-articular adhesion [2-6]. Hannafin and Chiaia [7] described FS as four stages including preadhesive, freezing, frozen, and thawing incorporating both clinical and arthroscopic findings [7].

Treatment options for frozen shoulder range from conservative treatments including physical therapy, therapeutic exercise, joint mobilization and manipulation, nonsteroidal anti-inflammatory and opioid medications, intra-articular steroid and hyaluronic acid injections, suprascapular nerve block, glenohumeral distention arthrography with and without steroid supplementation, and manipulation under general anesthesia to surgical intervention [8]. Regardless of modality, the goal of conservative treatment for FS is to reduce pain, restore function and motion of the shoulder, and improve quality of life [8].

Distention arthrography (DA) is an effective treatment for freezing or frozen stage of FS, where intracapsular pressure and volume are gradually increased through injection of fluid with local anesthetics with or without steroid supplementation until capsular rupture $[9,10]$. Clinically effective joint mobilization and manipulation improves tissue extensibility, reduces soft tissue swelling and inflammation, reduces pain, increases range of motion (ROM), and stimulates peripheral mechanoreceptors in FS [11]. Interestingly, the combination of DA and manipulation under general anesthesia leads to a rapid decrease in pain and an improvement of shoulder range of motion in patients 4 to 6 weeks after intervention [12].
However, to the best of our knowledge, no study has compared the therapeutic effect of DA with translational mobilization (TM) with DA alone in FS. Therefore, the objective of this study was to evaluate the therapeutic effectiveness and safety of DA alone and in combination with modified TM for the treatment of FS

\section{MATERIALS AND METHODS}

\section{Patients and study design}

This was a retrospective clinical study conducted with approval from the Institutional Review Board of Daegu Catholic University Medical Center (IRB No. CR-15-087). Informed consent was waived by the Institutional Review Board due to the retrospective nature of this investigation.

Eighty-five patients ( 51 females and 34 males; mean age, 63.3 years; range, 37-83 years) with unilateral idiopathic FS at freezing or frozen stages were recruited from the outpatient clinic of the Department of Rehabilitation Medicine.

Patients were eligible according to the following criteria: symptoms presented longer than 3 months, painful restriction of more than $30^{\circ}$ in shoulder passive range of motion (PROM) in at least 2 of 4 movement directions (forward flexion, abduction, external rotation, and internal rotation) of the affected shoulder compared with the unaffected shoulder [13], capsular pattern of motion restriction (proportional limitation of the three passive glenohumeral motions including more limitation of external rotation, some limitation of abduction, and less limitation of internal rotation), and normal shoulder radiographic finding.

Patients were excluded according to the following criteria: full-thickness or large partial-thickness rotator cuff tendon tear on magnetic resonance imaging (MRI) or ultrasound, calcific tendinitis, significant glenohumeral arthritis on radiograph, previous shoulder injury and surgery, mastectomy due to breast cancer, hemiplegic shoulder pain due to stroke, systemic inflammatory disease such as rheumatoid arthritis, presence or suspicion of infection, uncontrolled diabetes mellitus (DM), severe osteoporosis of humeral head on radiograph, and bleeding tendency or use of anticoagulant medication.

All patients with FS (freezing or frozen stage) were diagnosed by medical history, physical examination, ra- 
diograph, and all patients were evaluated by ultrasound or MRI. The patients were consecutively allocated into two groups (the first term, 44 patients; the last term, 41 patients). Forty-one patients ( 21 females and 20 males; mean age, 62.2 years; range, 37-83 years) received DA with TM (group 1) and 44 patients (30 females and 14 males; mean age, 67.5 years; range, $44-76$ years) received DA alone (group 2). DA and TM were performed only one time in all patients and TM was performed consecutively after DA. No significant difference in age was observed between the two patient groups. All patients received instruction for home-based exercise therapy for FS, but did not receive a physical therapy program. Lastly, use of nonsteroidal anti-inflammatory drugs (NSAIDs) was permitted following either procedure.

\section{Distention arthrography}

Before DA, a subacromial subdeltoid bursa was injected with lidocaine $(1 \%, 6 \mathrm{~mL})$ under ultrasound guidance $[14,15]$. All DA procedures were performed by a single physiatrist (GY Park) with 25 years of experience in musculoskeletal rehabilitation. All patients were first placed in the supine position and put under local anesthesia with $2 \%$ lidocaine. A 21 -gauge spinal needle was inserted at the anterior glenohumeral joint and advanced under fluoroscopic guidance. Correct placement of the spinal needle in the glenohumeral joint space was confirmed by injection of contrast medium (iopromide, Ultravist 300; Schering AG, Berlin, Germany). After confirming proper needle placement, a $16-\mathrm{mL}$ solution (4 $\mathrm{mL}$ of $50 \mathrm{mg} / 5 \mathrm{~mL}$ of triamcinolone acetonide, $6 \mathrm{~mL}$ of $2 \%$ lidocaine, and $6-7 \mathrm{~mL}$ of $0.9 \%$ sodium chloride) was slowly injected. In patients with DM, $3 \mathrm{~mL}$ of $50 \mathrm{mg} / 5$ $\mathrm{mL}$ of triamcinolone acetonide was used [16]. When resistance was felt during the injection, the injection was temporarily halted and subsequently resumed. DA was finished when the subscapular recess or long biceps tendon sheath were ruptured during the injection. If not ruptured after injection, shoulder PROM exercise was gently performed for 3 minutes by the physiatrist [17].
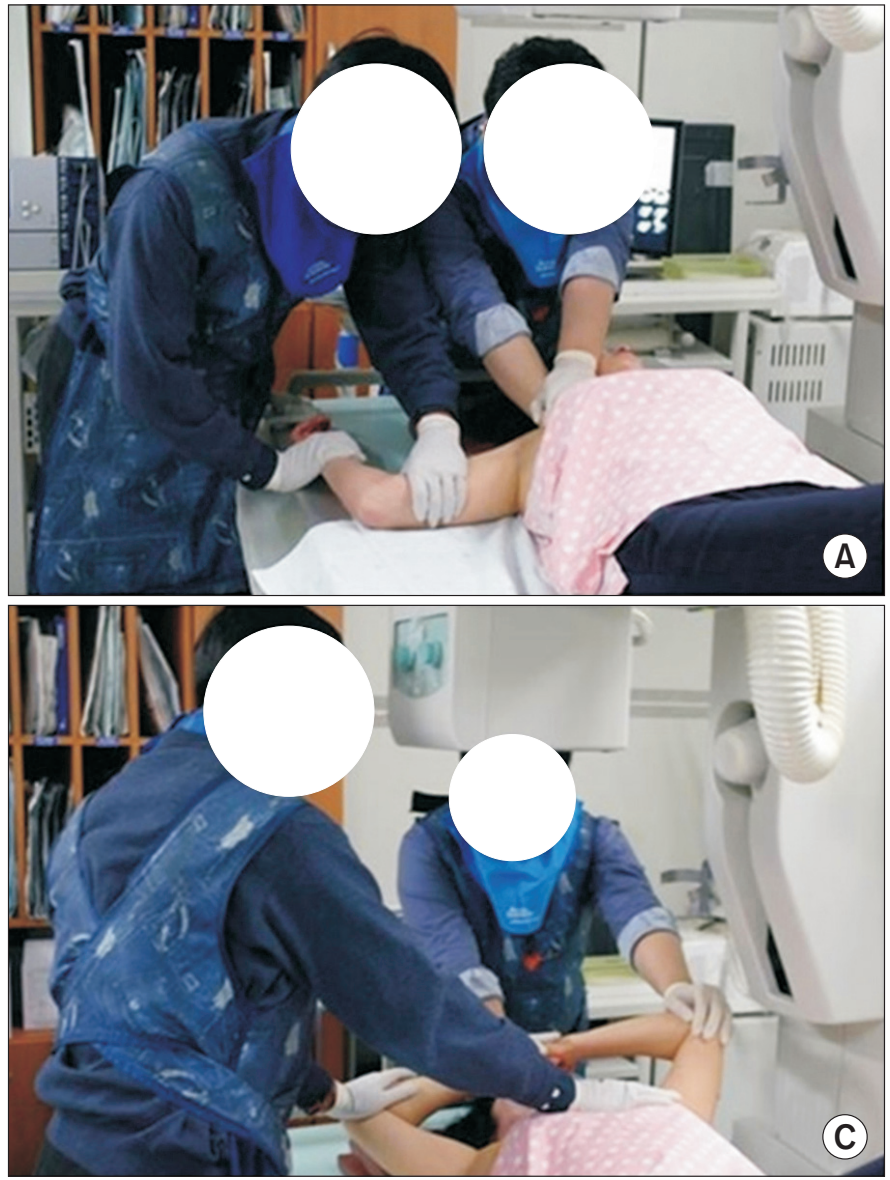

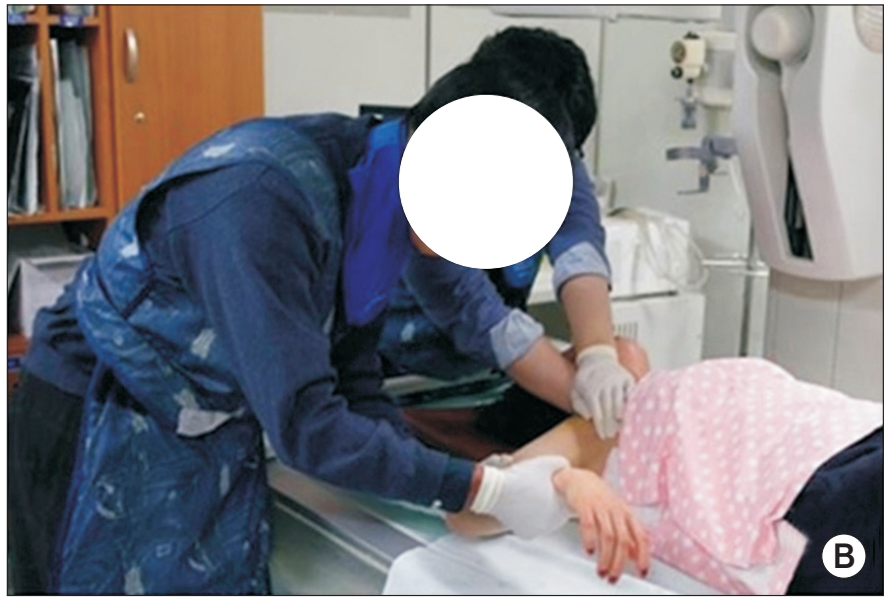

Fig. 1. Modified translational mobilization with capsular stretching. (A) Shoulder external rotation range at $90^{\circ}$ of abduction was gradually increased with posterior translation of humeral head and lateral traction. (B) Shoulder internal rotation range at $90^{\circ}$ of abduction was gradually increased with posterior translation of humeral head and lateral traction. (C) Cyriax's capsular stretching was performed using mobilization technique. 


\section{Translational mobilization}

Modified TM with capsular stretching was performed once at 5 minutes after DA by the physiatrist in group 1 patients. The patients were placed in the supine position. First, the manipulator's one hand was placed on the humeral head as close to joint space as possible with the other hand grasping the proximal humerus. Inferior translation force was applied by one hand simultaneously with lateral traction of the humerus applied by the other hand, and shoulder abduction range was gradually increased to the end of available shoulder abduction. Second, shoulder external rotation range at $90^{\circ}$ of abduction was gradually increased with lateral traction and posterior translation of the humeral head. Third, shoulder internal rotation range at $90^{\circ}$ of abduction was gradually increased with lateral traction and posterior translation of the humeral head [18]. Last, Cyriax's capsular stretching was performed using mobilization technique. Briefly, the patient brought one hand to their forehead and placed the other hand on top of the first hand. The manipulator standing on the affected side put one of their hands on the sternum and the other hand on the distal arm of the affected side. The manipulator gently pushed the distal arm backwards to the end of the available range [19] (Fig. 1).

\section{Clinical parameters}

Clinical parameters including visual analog scale (VAS), Cyriax stage (score range, 1-4), and shoulder PROM (forward flexion, abduction, external rotation, and internal rotation) were measured at baseline, 1 month, and 3 months after the treatment by the other physiatrist. The degree of shoulder pain was assessed using the $10-\mathrm{cm}$ pain VAS, where 0 indicates 'no pain' and 10 'worst pain possible' [20]. The passive forward flexion and abduction of shoulder were measured with the patient in the supine position, and passive external and internal rotations were measured at $90^{\circ}$ of abduction with scapular stabilization in supine position. Cyriax stage was assessed on a grade from 1 to 4 according to four criteria: the first three were provided by the clinical history of the patient (pain at rest, patient can lie on the affected side at night, and pain spread below the elbow) and the fourth was the end-feel during external rotation of the shoulder [19]. All outcome parameters were measured before treatment and at 1 and 3 months following intervention.

\section{Complication assessment}

Follow-up ultrasound of the affected shoulder was performed by the physiatrist with 25 years of experience in

Table 1. Demographic data and clinical parameters in patients with frozen shoulder

\begin{tabular}{|lccc}
\hline & Group 1 (n=41) & Group 2 (n=44) & p-value \\
\hline Age (yr) & $54.9 \pm 8.0$ & $56.0 \pm 9.2$ & 0.55 \\
\hline Gender & 19 & 14 & 0.13 \\
\hline Male & 23 & 30 & \\
\hline Female & & & 0.34 \\
\hline Location of shoulder pain & 21 & 18 & \\
\hline Right & 20 & 26 & 0.83 \\
\hline Left & 12 & 14 & 0.60 \\
\hline Diabetes mellitus & $6.3 \pm 6.1$ & $5.5 \pm 6.9$ & 0.40 \\
\hline Symptom duration (mo) & $7.7 \pm 1.7$ & $8.0 \pm 1.0$ & 0.09 \\
\hline VAS & $3.0 \pm 0.7$ & $2.7 \pm 0.7$ & \\
\hline Cyriax stage & & & 0.40 \\
\hline PROM $\left(^{\circ}\right)$ & $122.5 \pm 17.6$ & $119.4 \pm 16.5$ & 0.44 \\
\hline Flexion & $111.4 \pm 25.8$ & $115.4 \pm 22.3$ & 0.13 \\
\hline Abduction & $34.7 \pm 15.2$ & $39.4 \pm 13.1$ & 0.49 \\
\hline External rotation & $20.2 \pm 9.6$ & $21.6 \pm 9.5$ & \\
\hline Internal rotation & & & \\
\hline
\end{tabular}

Values are presented as mean \pm standard deviation.

Group 1, distention arthrography with translational mobilization; Group 2, distention arthrography alone; VAS, visual analogue scale; PROM, passive ranges of motion. 
musculoskeletal ultrasound immediately after DA with TM to identify potential complications associated with intervention.

\section{Statistical analyses}

Statistical analyses were performed using SPSS version 19.0 (IBM Corporation, Armonk, NY, USA), with the level of significance set at $\mathrm{p}<0.05$. Independent $t$-test was used for the difference of age, symptom duration, and four shoulder PROMs between two groups. The MannWhitney U-test was used for VAS and Cyriax stage, and the chi-square test was used for gender, affected side, the presence of DM at baseline. Repeated measures analysis of variance (ANOVA) was used to examine the intragroup differences for effect of time. Intergroup differences in the outcome measurements were evaluated using MannWhitney U-test. The post-hoc power analysis was performed using G*Power 3 (Heinrich-Heine-University, Dusseldorf, Germany) and the power (1- $\beta$ ) was $0.47-0.99$.

\section{RESULTS}

At baseline, there were no significant differences in patient gender, affected side, symptom duration, presence of DM, and all clinical parameters including VAS score, Cyriax stage, and shoulder PROM between the treatment groups (Table 1). All clinical parameters were significantly improved in both groups at all post-treatment time points compared to baseline parameters $(\mathrm{p}=0.000)$ (Table 2). However, all mean PROMs at 1 and 3 months follow- ing treatment were significantly greater in FS patients receiving DA and TM therapy-flexion at 1 and 3 months after treatment (1/3MAT) $(\mathrm{p}=0.008$ and $\mathrm{p}=0.047)$, abduction at $1 / 3$ MAT $(\mathrm{p}=0.038$ and $\mathrm{p}=0.000$, external rotation at $1 / 3$ MAT $(\mathrm{p}=0.009$ and $\mathrm{p}=0.009)$, internal rotation at 1/3MAT ( $\mathrm{p}=0.045$ and $\mathrm{p}=0.049$ ) (Table 2). Relative to DA alone, the combination of DA and TM therapy also significantly decreased mean VAS score and Cyriax stage in FS patients at one and three months post-intervention-VAS at $1 / 3$ MAT $(\mathrm{p}=0.000$ and $\mathrm{p}=0.032)$, Cyriax stage at $1 / 3 \mathrm{MAT}$ $(\mathrm{p}=0.002$ and $\mathrm{p}=0.000)$ (Table 2). The mean interval change of clinical parameters between baseline and at 1 and 3 months (1/3IC) after treatment were significantly greater in patients receiving the combination DA and TM therapy-VAS $1 / 3 \mathrm{IC}(\mathrm{p}=0.031$ and $\mathrm{p}=0.243$ ), Cyriax stage $1 / 3$ IC $(p=0.000$ and $p=0.000)$, flexion $1 / 3$ IC $(p=0.008$ and $\mathrm{p}=0.031)$, abduction $1 / 3 \mathrm{IC}(\mathrm{p}=0.001$ and $\mathrm{p}=0.000)$, external rotation $1 / 3 \mathrm{IC}(\mathrm{p}=0.000$ and $\mathrm{p}=0.000)$, internal rotation $1 / 3 \mathrm{IC}(\mathrm{p}=0.007$ and $\mathrm{p}=0.000)$ (Table 3 ). Capsular rupture sites in patients receiving both DA and TM were as follows: 21 subscapular recess ruptures, 15 subscapular and axillary recesses ruptures, 3 axillary recess ruptures, 1 long biceps tendon sheath rupture, and 1 axillary recess and long biceps tendon sheath rupture. Conversely, patients receiving DA alone presented 38 subscapularis recess ruptures, 2 long biceps tendon sheath ruptures, and 1 subscapularis and axillary recesses rupture (Table 4 ). No serious complications, such as fracture, glenohumeral dislocation, peripheral nerve injury, rotator cuff tear, and infection, were observed following either treatment.

Table 2. Comparison of clinical parameters between distention arthrography with and without translational mobilization

\begin{tabular}{|c|c|c|c|c|c|c|}
\hline & \multicolumn{3}{|c|}{ Group 1} & \multicolumn{3}{|c|}{ Group 2} \\
\hline & Baseline & 1MAT & 3MAT & Baseline & IMAT & 3MAT \\
\hline VAS & $7.7 \pm 1.7$ & $2.7 \pm 1.1^{\mathrm{a}, \mathrm{b})}$ & $2.2 \pm 1.2^{\mathrm{a}, \mathrm{b})}$ & $8.0 \pm 1.0$ & $3.8 \pm 1.3^{\mathrm{a}, \mathrm{b})}$ & $2.7 \pm 1.0^{\mathrm{a}, \mathrm{b})}$ \\
\hline Cyriax stage & $3.0 \pm 0.7$ & $1.4 \pm 0.5^{\mathrm{a}, \mathrm{b})}$ & $1.1 \pm 0.3^{\mathrm{a}, \mathrm{b})}$ & $2.7 \pm 0.7$ & $1.9 \pm 0.5^{\mathrm{a}, \mathrm{b})}$ & $1.6 \pm 0.5^{\mathrm{a}, \mathrm{b})}$ \\
\hline \multicolumn{7}{|l|}{$\operatorname{PROM}\left(^{\circ}\right)$} \\
\hline Flexion & $122.5 \pm 17.6$ & $150.1 \pm 16.1^{\mathrm{a}, \mathrm{b})}$ & $163.1 \pm 14.9^{\mathrm{a}, \mathrm{b})}$ & $119.4 \pm 16.5$ & $139.7 \pm 17.8^{\mathrm{a}, \mathrm{b})}$ & $150.2 \pm 17.2^{\mathrm{a}, \mathrm{b})}$ \\
\hline Abduction & $111.4 \pm 25.8$ & $155.6 \pm 26.3^{\mathrm{a}, \mathrm{b})}$ & $171.2 \pm 15.3^{\mathrm{a}, \mathrm{b})}$ & $115.4 \pm 22.3$ & $145.1 \pm 23.0^{\mathrm{a}, \mathrm{b})}$ & $156.7 \pm 21.4^{\mathrm{a}, \mathrm{b})}$ \\
\hline External rotation & $34.7 \pm 15.2$ & $63.2 \pm 15.8^{\mathrm{a}, \mathrm{b})}$ & $74.5 \pm 15.4^{\mathrm{a}, \mathrm{b})}$ & $39.4 \pm 13.1$ & $54.8 \pm 14.5^{\mathrm{a}, \mathrm{b})}$ & $63.5 \pm 14.6^{\mathrm{a}, \mathrm{b})}$ \\
\hline Internal rotation & $20.2 \pm 9.6$ & $34.4 \pm 8.1^{\mathrm{a}, \mathrm{b})}$ & $39.9 \pm 9.6^{\mathrm{a}, \mathrm{b}}$ & $21.6 \pm 9.5$ & $31.6 \pm 9.1^{\mathrm{a}, \mathrm{b})}$ & $36.5 \pm 8.5^{\mathrm{a}, \mathrm{b})}$ \\
\hline
\end{tabular}

Values are presented as mean \pm standard deviation.

Group 1, distention arthrography with translational mobilization; Group 2, distention arthrography alone; 1MAT, 1 month after treatment; 3MAT, 3 months after treatment; VAS, visual analogue scale; PROM, passive ranges of motion. ${ }^{a)} \mathrm{p}<0.05$ by Mann-Whitney $U$-test between groups 1 and 2 at 1 and 3 months after treatment.

${ }^{b)} \mathrm{p}<0.05$ from repeated measures ANOVA for effect of time. 
Table 3. Comparison of interval change of clinical parameters between distention arthrography with and without translational mobilization

\begin{tabular}{|c|c|c|c|c|}
\hline & \multicolumn{2}{|c|}{ Group 1} & \multicolumn{2}{|c|}{ Group 2} \\
\hline & 1IC & 3IC & 1IC & 3IC \\
\hline VAS & $5.0 \pm 1.5^{\mathrm{a})}$ & $5.5 \pm 1.6$ & $4.1 \pm 1.4^{\mathrm{a})}$ & $5.2 \pm 1.2$ \\
\hline Cyriax stage & $1.6 \pm 0.6^{\mathrm{a})}$ & $1.8 \pm 0.7^{\mathrm{a})}$ & $0.8 \pm 0.6^{\mathrm{a})}$ & $1.0 \pm 0.6^{\mathrm{a})}$ \\
\hline \multicolumn{5}{|l|}{$\operatorname{PROM}\left({ }^{\circ}\right)$} \\
\hline Flexion & $27.5 \pm 13.6^{\text {a) }}$ & $40.6 \pm 17.2^{\mathrm{a})}$ & $20.3 \pm 8.7^{\text {a) }}$ & $30.8 \pm 11.6^{\mathrm{a})}$ \\
\hline Abduction & $44.1 \pm 21.9^{a)}$ & $59.7 \pm 22.2^{\mathrm{a})}$ & $29.6 \pm 18.4^{\mathrm{a})}$ & $41.2 \pm 20.0^{\mathrm{a})}$ \\
\hline External rotation & $28.5 \pm 15.0^{\mathrm{a})}$ & $39.7 \pm 18.1^{\text {a) }}$ & $15.3 \pm 8.8^{\mathrm{a})}$ & $24.0 \pm 11.7^{\mathrm{a})}$ \\
\hline Internal rotation & $14.2 \pm 6.9^{\mathrm{a})}$ & $19.7 \pm 9.8^{\mathrm{a})}$ & $10.0 \pm 9.0^{\mathrm{a})}$ & $14.9 \pm 9.5^{\mathrm{a})}$ \\
\hline
\end{tabular}

Values are presented as mean \pm standard deviation.

Group 1, distention arthrography with translational mobilization; Group 2, distention arthrography alone; 1IC, interval change of clinical parameters between baseline and 1 month after treatment; 3IC, interval change of clinical parameters between baseline and 3 months after treatment; VAS, visual analogue scale; PROM, passive ranges of motion.

${ }^{a)} \mathrm{p}<0.05$ by Mann-Whitney U-test between groups 1 and 2 .

Table 4. Comparison of capsular rupture site between distention arthrography with and without translational mobilization

\begin{tabular}{lcc|}
\hline \multicolumn{1}{c}{ Capsular rupture site } & Group 1 & Group 2 \\
\hline Subscapular recess & 21 & 38 \\
\hline Subscapular recess+axillary recess & 15 & 0 \\
\hline Axillary recess & 3 & 0 \\
\hline Long biceps tendon sheath & 1 & 2 \\
\hline $\begin{array}{l}\text { Subscapular recess+long biceps } \\
\text { tendon sheath }\end{array}$ & 0 & 1 \\
$\begin{array}{l}\text { Axillary recess+long biceps tendon } \\
\text { sheath }\end{array}$ & 1 & 0 \\
\hline
\end{tabular}

Group 1, distention arthrography with translational mobilization; Group 2, distention arthrography alone.

\section{DISCUSSION}

The results demonstrate that the combination of DA with TM is a safe and effective treatment to reduce persistent pain and restricted mobility found in patients with freezing or frozen stage FS. Additionally, all clinical outcome parameters including pain (VAS score), PROM, and Cyriax stage were significantly improved at one and three months following DA alone, consistent with previous studies $[21,22]$. In unafflicted patients, normal shoulder joint capacity was greater than $16 \mathrm{~mL}$, whereas it was less than $10 \mathrm{~mL}$ in patients with FS [23]. Mao et al. [24] reported the correlation between shoulder joint space capacity and shoulder ROM. Both the shoulder ROM including flexion, abduction, external rotation, and internal rotation and the shoulder joint capacity measured by arthrography were significantly increased after conservative treatments including physical modalities and exercise. However, the increased shoulder joint capacity was only significantly correlated with increased external rotation. DA combined with steroid injection revealed better improvement of shoulder ROM than steroid injection alone in patients with FS [21]. Furthermore, steroid injection with repeated DA was more effective in reducing patient disability and pain compared with a single DA treatment [22].

Placzek et al. [25] reported the long-term effects of translational manipulation about ROM, function, and pain in patients with FS and concluded that translational manipulation is a valid, biomechanically excellent treatment for FS. The same authors also reported increased shoulder ROM and decreased pain at 14 months after translational manipulation in FS, and typical cracking sound known as characteristic crepitus could be heard during manipulation. This sound was believed to reflect the loosening and tearing of the adhesive shoulder joint capsule $[26,27]$. Although not directly associated with pain relief, this cracking sound was correlated with improvement of shoulder external rotation [28]. In our study, the manipulator experienced the cracking sound during TM with shoulder external rotation in most cases and the increased ROM immediately after cracking sound [29]. 
Combination treatment using DA with manipulation under general anesthesia was first reported by Ekelund and Rydell [12] and resulted in a rapid decrease in pain and increase in shoulder ROM at 4 to 6 weeks after intervention. The combination of DA and manipulation under local anesthesia provided sufficient improvement in shoulder ROM, and was regarded as a safe and effective treatment for FS [30]. Choi et al. [28] reported that DA with manipulation in FS patients led to a reduction in pain and improvements in both shoulder ROM and general function. In agreement with the previous studies, our data indicate that DA with TM resulted in significant improvements in all clinical parameters including VAS, Cyriax stage, and all shoulder PROMs at 1 and 3 months following treatment.

Additionally, the interval change of all clinical parameters was significantly greater in FS patients receiving DA with TM than those receiving DA alone. As a possible explanation of this finding, TM combined with DA might effectively resolve the residual deficit in shoulder motion present following DA alone. In our study, subscapular recess was usually ruptured after DA alone, but axillary recess was ruptured together with subscapular recess rupture after DA with TM.

Instead of manipulation requiring general or local anesthesia via suprascapular and/or axillary nerve block, we performed a modified TM technique with capsular stretching after DA. For pain control during DA and DA with TM, subacromial subdeltoid bursa was injected with local anesthetics before the treatments. Uncontrolled shoulder joint manipulation may cause structural damage to cartilage and soft tissue of the glenohumeral joint. Furthermore, manipulation under general anesthesia in FS can cause iatrogenic injury, such as humeral neck fracture, axillary or radial nerve injury, superior labrum anterior-posterior lesion, partial-thickness tear of rotator cuff tendon, labral detachment, and glenohumeral ligament tear [12]. In our study, no serious complications were associated with either procedure as assessed by ultrasound following treatment. There are several possible explanations for this finding. First, DA will reduce capsular adhesion of FS before TM, protecting the soft tissues surrounding the shoulder during TM. Second, instead of manipulation, we employed a short lever mobilization technique. Contrary to traditional long lever angular manipulation, short lever mobilization of the shoulder will reduce the inflicting force applied to the shoulder during treatment. Finally, all procedures were performed by the skilled physiatrist with 20 years of experience in manual medicine.

There are several limitations to this study. First, the sample size was relatively small. Therefore, serious complication could not happen because of the small number of patients. Second, the follow-up period after treatment was short. Third, this was a retrospective study and we cannot exclude the possibility of inherent patient selection bias. However, this is the first study to compare the therapeutic effect of DA alone with combination DA and TM therapy in FS patients. Further prospective study with a larger sample size, long-term follow-up, and doubleblinded control will be necessary to confirm the validity of our study results.

In conclusion, the combination of TM with DA significantly decreased shoulder pain and increased shoulder PROM without serious complications in patients with freezing or frozen stage FS. Furthermore, compared to DA alone, our results indicate that DA in combination with TM may be more therapeutically effective for FS treatment.

\section{CONFLICT OF INTEREST}

No potential conflict of interest relevant to this article was reported.

\section{REFERENCES}

1. Codman EA. The shoulder: rupture of the suprasupinatus tendon. Boston: Todd Company; 1934. p. 21624.

2. Neviaser JS. Adhesive capsulitis of the shoulder: a study of the pathological findings in periarthritis of the shoulder. J Bone Joint Surg Am 1945;27:211-22.

3. Ha'eri GB, Maitland A. Arthroscopic findings in the frozen shoulder. J Rheumatol 1981;8:149-52.

4. Kilian O, Kriegsmann J, Berghauser K, Stahl JP, Horas U, Heerdegen R. The frozen shoulder: arthroscopy, histological findings and transmission electron microscopy imaging. Chirurg 2001;72:1303-8.

5. Uitvlugt G, Detrisac DA, Johnson LL, Austin MD, Johnson C. Arthroscopic observations before and after manipulation of frozen shoulder. Arthroscopy 
1993;9:181-5.

6. Wiley AM. Arthroscopic appearance of frozen shoulder. Arthroscopy 1991;7:138-43.

7. Hannafin JA, Chiaia TA. Adhesive capsulitis: a treatment approach. Clin Orthop Relat Res 2000;372:95109.

8. Mitra R, Harris A, Umphrey C, Smuck M, Fredericson M. Adhesive capsulitis: a new management protocol to improve passive range of motion. PM R 2009;1: 1064-8.

9. Simpson JK, Budge R. Treatment of frozen shoulder using distension arthrography (hydrodilatation): a case series. Australas Chiropr Osteopathy 2004;12:2535.

10. Andren L, Lundberg BJ. Treatment of rigid shoulders by joint distension during arthrography. Acta Orthop Scand 1965;36:45-53.

11. Haines JF, Hargadon EJ. Manipulation as the primary treatment of the frozen shoulder. J R Coll Surg Edinb 1982;27:271-5.

12. Ekelund AL, Rydell N. Combination treatment for adhesive capsulitis of the shoulder. Clin Orthop Relat Res 1992;282:105-9.

13. Tveita EK, Tariq R, Sesseng S, Juel NG, Bautz-Holter E. Hydrodilatation, corticosteroids and adhesive capsulitis: a randomized controlled trial. BMC Musculoskelet Disord 2008;9:53.

14. Oh JH, Oh CH, Choi JA, Kim SH, Kim JH, Yoon JP. Comparison of glenohumeral and subacromial steroid injection in primary frozen shoulder: a prospective, randomized short-term comparison study. J Shoulder Elbow Surg 2011;20:1034-40.

15. Cole BF, Peters KS, Hackett L, Murrell GA. Ultrasoundguided versus blind subacromial corticosteroid injections for subacromial impingement syndrome: a randomized, double-blind clinical trial. Am J Sports Med 2016;44:702-7.

16. Kim YS, Lee HJ, Lee DH, Choi KY. Comparison of high- and low-dose intra-articular triamcinolone acetonide injection for treatment of primary shoulder stiffness: a prospective randomized trial. J Shoulder Elbow Surg 2017;26:209-15.

17. Kim JS, Kwon JY, Lee WI, Kim JM. The additional effect of tear after passive exercise during distension arthrography in patients with frozen shoulder. J Korean Acad Rehabil Med 2008;32:324-6.
18. Roubal PJ, Dobritt D, Placzek JD. Glenohumeral gliding manipulation following interscalene brachial plexus block in patients with adhesive capsulitis. J Orthop Sports Phys Ther 1996;24:66-77.

19. Cyriax JH. Textbook of orthopaedic medicine (Volume 1. Diagnosis of soft tissue lesions). 7th ed. London: Harcourt Publisher; 1978. p. 224-5.

20. Hartrick CT, Kovan JP, Shapiro S. The numeric rating scale for clinical pain measurement: a ratio measure? Pain Pract 2003;3:310-6.

21. Gam AN, Schydlowsky P, Rossel I, Remvig L, Jensen EM. Treatment of "frozen shoulder" with distension and glucorticoid compared with glucorticoid alone: a randomised controlled trial. Scand J Rheumatol 1998;27:425-30.

22. Piotte F, Gravel D, Moffet H, Fliszar E, Roy A, Nadeau $S$, et al. Effects of repeated distension arthrographies combined with a home exercise program among adults with idiopathic adhesive capsulitis of the shoulder. Am J Phys Med Rehabil 2004;83:537-46.

23. Lundberg BJ. The frozen shoulder: clinical and radiographical observations; the effect of manipulation under general anesthesia; structure and glycosaminoglycan content of the joint capsule; and local bone metabolism. Acta Orthop Scand Suppl 1969;119:1-59.

24. Mao CY, Jaw WC, Cheng HC. Frozen shoulder: correlation between the response to physical therapy and follow-up shoulder arthrography. Arch Phys Med Rehabil 1997;78:857-9.

25. Placzek JD, Roubal PJ, Freeman DC, Kulig K, Nasser S, Pagett BT. Long-term effectiveness of translational manipulation for adhesive capsulitis. Clin Orthop Relat Res 1998;356:181-91.

26. Amoretti N, Grimaud A, Brocq O, Roux C, Dausse F, Fournol M, et al. Shoulder distension arthrography in adhesive capsulitis. Clin Imaging 2006;30:254-6.

27. Loew M, Heichel TO, Lehner B. Intraarticular lesions in primary frozen shoulder after manipulation under general anesthesia. J Shoulder Elbow Surg 2005;14:1621.

28. Choi JK, Son SB, Park BJ, Yang SN, Yoon JS. Shoulder manipulation after distention arthrography: does audible cracking affect improvement in adhesive capsulitis? A preliminary study. Ann Rehabil Med 2015;39:745-51.

29. Flannery O, Mullett H, Colville J. Adhesive shoulder 
Gi Young Park, et al.

capsulitis: does the timing of manipulation influence outcome? Acta Orthop Belg 2007;73:21-5.

30. van Royen BJ, Pavlov PW. Treatment of frozen shoul- der by distension and manipulation under local anaesthesia. Int Orthop 1996;20:207-10. 